\title{
Inadvertent Right Ventricle Perforation by Temporary Pacemaker Lead: A Case Report Requiring Surgical Exploration
}

\author{
Surendra Jangid ${ }^{1}$ Devishree Das ${ }^{1} \quad$ Minati Choudhury ${ }^{1}$ \\ ${ }^{1}$ Department of Cardiac Anaesthesia, Cardiothoracic Centre, CNC, \\ All India Institute of Medical Sciences, Ansari Nagar, New Delhi, \\ India

\begin{abstract}
Address for correspondence Surendra Jangid, MD, Cardiothoracic Centre, All India Institute of Medical Sciences, Ansari Nagar, New Delhi, 110029, India (e-mail: dr.skjangid@gmail.com).
\end{abstract}

\begin{abstract}
Keywords

- perforation

- right ventricle

- temporary pacemaker

Right ventricle perforation by pacemaker lead is rare but a life-threatening complication. It may present acutely within few hours of pacemaker implantation as hemopericardium, dreaded cardiac tamponade, leading to acute hemodynamic deterioration; even death, if not address immediately. At times, it presents gradually with progressive decline in hemodynamic and requires surgical exploration.

The authors report a case of 51-year old female whose hemodynamic worsens gradually after temporary pacemaker implantation, requiring surgical exploration.
\end{abstract}

\section{Introduction}

In the present era, the incidence of complications after pacemaker implantation is 3 to $7.5 \%{ }^{1}$ With advancement of technology and scientific skill, the rate of pacemaker insertion as therapeutic intervention for arrhythmia is multiplying. As a consequence, the diversity of complication is also intensifying. ${ }^{2}$ Therefore, the hemodynamic of a patient is carefully and skillfully followed-up to avoid inevitable situations and complications, which need to be addressed as early as possible.

\section{Case Report}

A 51-year old female presented to the emergency room with complain of breathlessness and sudden loss of consciousness lasting for 2 to 4 minutes. The patient was a known case of hypertension for 2 years and on regular antihypertensive medication. She had five to six episodes of dizziness on standing in the previous month. On ECG, left ventricular hypertrophy with right bundle branch block (RBBB) and left anterior hemiblock was found. As the heart rate (HR) was low, and the patient was symptomatic, temporary pacemaker was inserted through right femoral vein under fluoroscopic guidance. Further, the patient was planned for elective permanent pacemaker implantation through subclavian vein.

After implantation of permanent pacemaker, the hemodynamic deteriorated gradually over 2 days. On transthoracic echocardiography, pericardial effusion with inhomogeneous clot was found anterior to the right ventricle. Therefore, surgical exploration was planned.

After shifting to the operation theater, a large bore intravenous (IV) and arterial access was obtained under local anesthesia (LA). Thereafter, the patient was induced, and airway was secured. The central venous cannula was secured. On transesophageal echocardiography, we found a pacemaker lead peeping in the pericardial cavity ( - Fig. 1, - Video 1 ), leading to pericardial effusion ( - Fig. 2, - Video 2 ) and hemodynamic deterioration.
DOI https://doi.org/ $10.1055 / \mathrm{s}-0041-1724144$ ISSN 2457-0206. (c) 2021. Official Publication of The Simulation Society (TSS), accredited by International Society of Cardiovascular Ultrasound (ISCU).

This is an open access article published by Thieme under the terms of the Creative Commons Attribution-NonDerivative-NonCommercial-License, permitting copying and reproduction so long as the original work is given appropriate credit. Contents may not be used for commercial purposes, or adapted, remixed, transformed or built upon. (https://creativecommons.org/licenses/by-nc-nd/4.0/)

Thieme Medical and Scientific Publishers Pvt. Ltd., A-12, 2nd Floor, Sector 2, Noida-201301 UP, India 


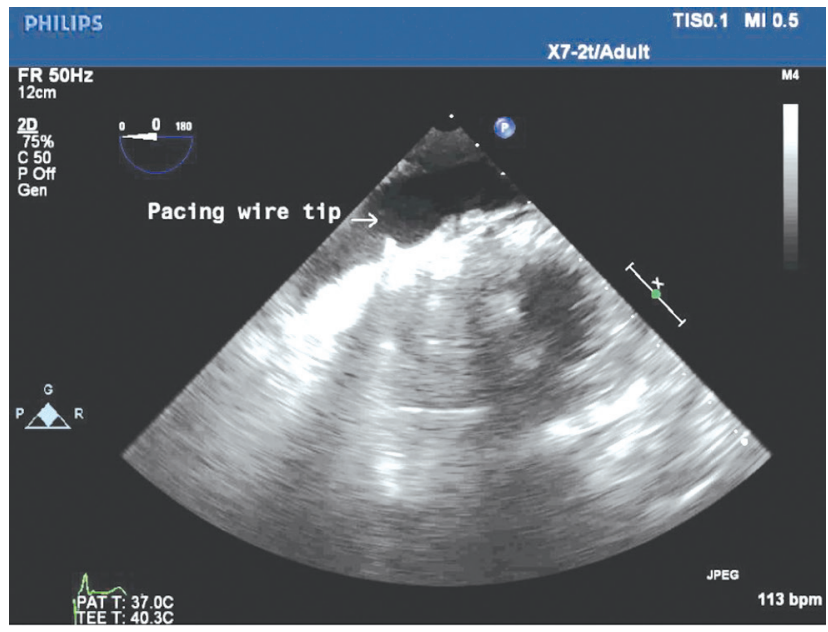

Fig. 1 Transgastric apical short axis view showing pacing wire perforating right ventricle $(\mathrm{RV})>$.

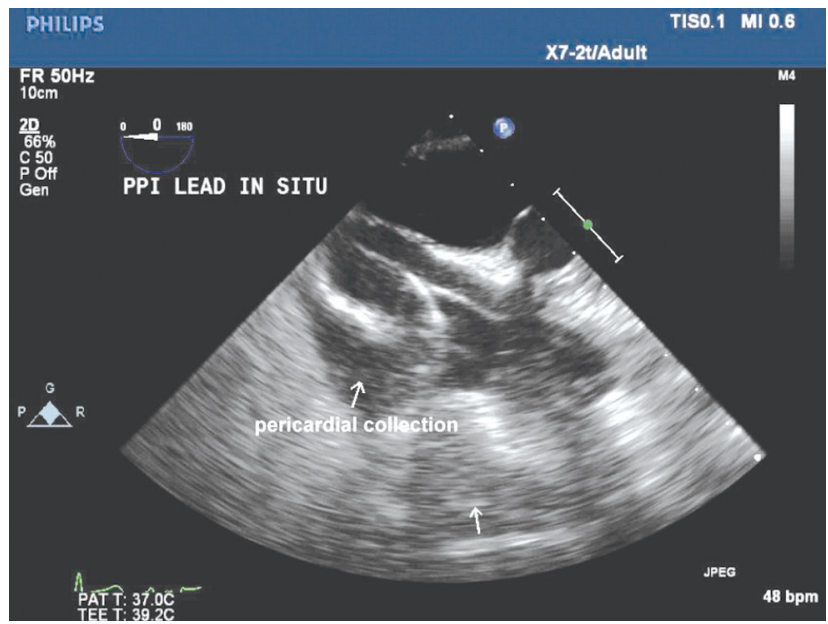

Fig. 2 Midesophageal 4-chamber view showing multiple pacing wires and pericardial collection.

\section{Video 1}

Transgastric apical short axis view showing pacing wire perforating right ventricle (RV). Online content including video sequences viewable at: https:// www.thieme-connect.com/products/ejournals/ html/10.1055/s-0041-1724144.

\section{Video 2}

Midesophageal 4-chamber view showing multiple pacing wires and pericardial collection. Online content including video sequences viewable at: https:// www.thieme-connect.com/products/ejournals / html/10.1055/s-0041-1724144.
Subsequently, median sternotomy was done, and pericardial blood was drained. The pacemaker lead was found to be protruding from the right ventricle ( - Fig. 3, - Video 3 ). The pacemaker lead was withdrawn through femoral line and right ventricle (RV) wall was repaired. The vitals improved after evacuation of pericardial clot and drainage of pericardial collections. The postoperative course was uneventful, and after 5 days of hospital stay, the patient was discharged.

\section{Video 3}

After pericardial opening pacing, wire was found to be perforating right ventricle(RV). Online content including video sequences viewable at: https://www.thieme-connect. com/products/ejournals/html/10.1055/s-0041-1724144.

\section{Discussion}

The myocardial perforation after pacemaker implantation has diverse clinical spectrum. The most frequently and dreaded complication constitutes pneumothorax (1.9-3.7\%), lead displacement (0.5-4.8), and cardiac perforation $(0.37-1 \%), 3,4,5$ The cardiac perforation causing rapid hemodynamic instability can present acutely within 24 hours after insertion, subacutely within 1 month, or chronically after 1 month of implantation. ${ }^{6}$

Cardiac perforation can affect any part that comes in contact with lead. Perforation through RV apex is common, life-threatening, and requires surgical assistance. Chest X-ray and echocardiography are the useful tools for diagnosis. Echocardiography also quantitates the pericardial effusion

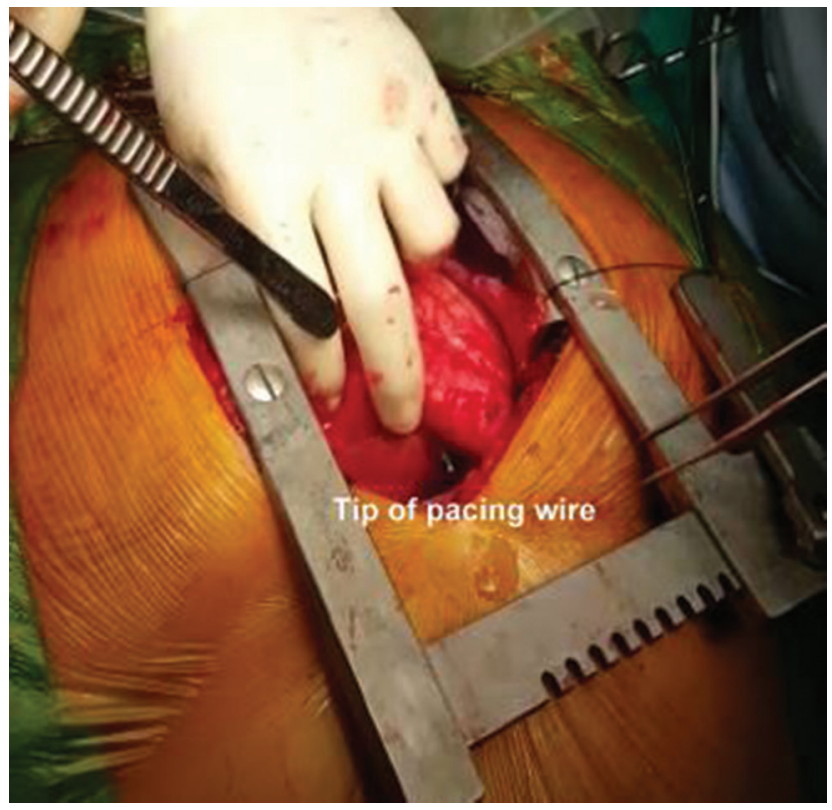

Fig. 3 After pericardial opening pacing, wire was found to be perforating right ventricle (RV). 
and forms the first line of defense in an emergency situation. The pericardial tamponade needs urgent evacuation or drainage over a period of time, depending on the quantity. The ventricular repair may be managed conservatively by lead extraction or may need surgical exploration.

In our case, the temporary pacemaker lead caused RV perforation, which was detected after 2 days of permanent pacemaker implantation. This was subacute in nature and gradually progressive, causing hemodynamic deterioration of patient. Echocardiography played an important role to not only detect the perforation but also identify the urgency of surgery due to development of granulation tissue near the perforation site, which cannot be managed conservatively by simply lead extraction.

\section{Conclusion}

The implantation rates of pacemaker have steadily increased over the last two decades and so has the heterogeneity of complication. Therefore, RV rupture after pacemaker implantation is not uncommon. The conservative management in the form of simply lead extraction is not advisable always, and patient should be stratified and managed skillfully.

\section{Conflict of Interest}

None declared.

\section{Acknowledgment}

We acknowledge the surgical and cardiology teams for the roles they played in managing the case.

\section{References}

1 Ellenbogen KA, Hellkamp AS, Wilkoff BL, et al. Complications arising after implantation of DDD pacemakers: the MOST experience. Am J Cardiol 2003;92(6):740-741

2 Bradshaw PJ, Stobie P, Knuiman MW, Briffa TG, Hobbs MST. Trends in the incidence and prevalence of cardiac pacemaker insertions in an ageing population. Open Heart 2014;1(1):e000177-e000177

3 Tobin K, Stewart J, Westveer D, Frumin H. Acute complications of permanent pacemaker implantation: their financial implication and relation to volume and operator experience. Am J Cardiol 2000;85(6):774-776, A9

4 Aggarwal RK, Connelly DT, Ray SG, Ball J, Charles RG. Early complications of permanent pacemaker implantation: no difference between dual and single chamber systems. Br Heart J 1995;73(6):571-575

5 Link MS, Estes NA III, Griffin JJ, et al; Pacemaker Selection in the Elderly (PASE) Investigators. Complications of dual chamber pacemaker implantation in the elderly. J Interv Card Electrophysiol 1998;2(2):175-179

6 Laborderie J, Barandon L, Ploux S, et al. Management of subacute and delayed right ventricular perforation with a pacing or an implantable cardioverter-defibrillator lead. Am J Cardiol 2008;102(10):1352-1355 